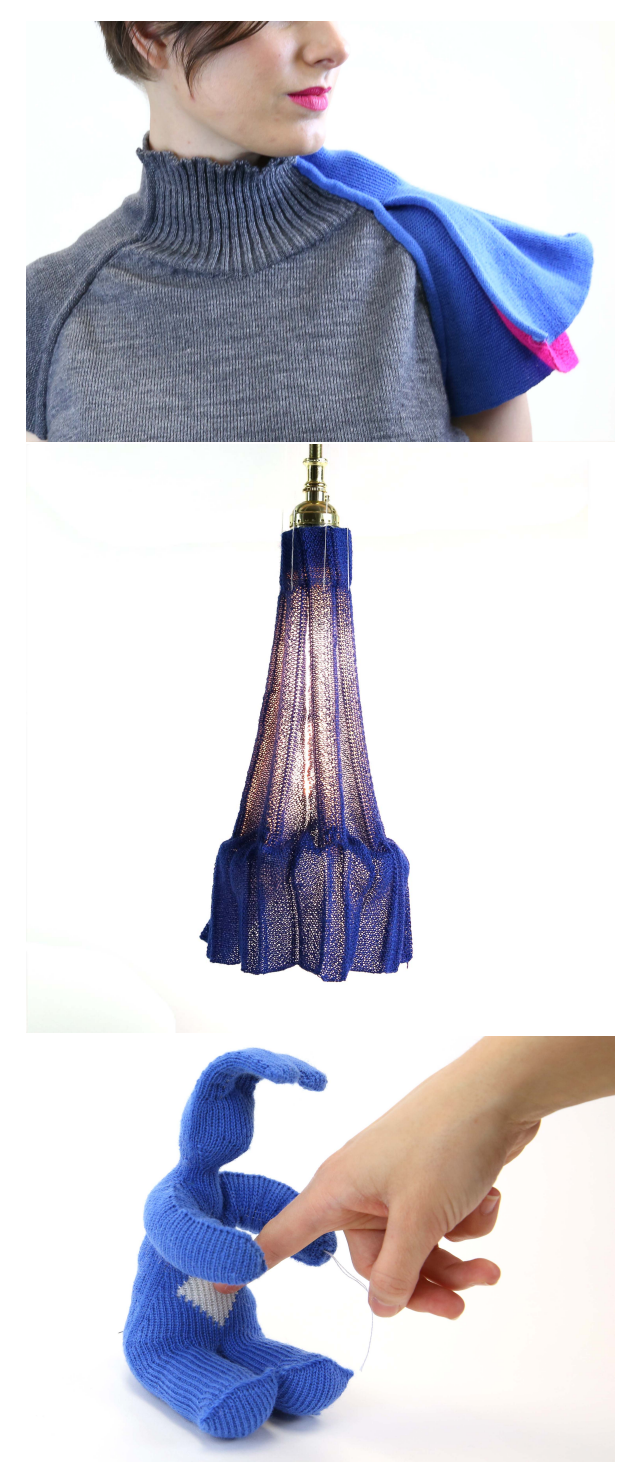

\title{
Digital Fabrication of Soft Actuated Objects by Machine Knitting
}

\author{
Lea Albaugh \\ Scott Hudson \\ Lining Yao \\ Carnegie Mellon University Human-Computer Interaction Institute \\ \{lea,scott.hudson,liningy\}@cs.cmu.edu
}

\begin{abstract}
With recent interest in shape-changing interfaces, material-driven design, wearable technologies, and soft robotics, digital fabrication of soft actuatable material is increasingly in demand. Much of this research focuses on elastomers or non-stretchy air bladders. Computationally-controlled machine knitting offers an alternative fabrication technology which can rapidly produce soft textile objects that have a very different character: breathable, lightweight, and pleasant to the touch. These machines are well established and optimized for the mass production of garments, but have received much less attention as general purpose fabrication device compared to other digital fabrication techniques such as CNC machining or 3D printing. This video showcases the results of our associated CHI 2019 paper [1] on design strategies for machine knitting actuated soft objects by integrating tendons with shaping and anisotropic texture design.
\end{abstract}

\section{References}

[1] Lea Albaugh, Scott Hudson, and Lining Yao. 2019. Digital Fabrication of Soft Actuated Objects by Machine Knitting. CHI Conference on Human Factors in Computing Systems Proceedings (2019), 13.

Permission to make digital or hard copies of part or all of this work for personal or classroom use is granted without fee provided that copies are not made or distributed for profit or commercial advantage and that copies bear this notice and the full citation on the first page. Copyrights for third-party components of this work must be honored. For all other uses, contact the owner/author(s).

CHI'19 Extended Abstracts, May 4-9, 2019, Glasgow, Scotland UK

(c) 2019 Copyright held by the owner/author(s).

ACM ISBN 978-1-4503-5971-9/19/05.

https://doi.org/10.1145/3290607.3311767 